What Gets Lost When English Only Writing Assessment Is Used to Assess Writing Proficiency in Spanish-English Emerging Bilingual Learners?

\author{
Kathy Escamilla, Sandra Butvilofsky, and Susan Hopewell \\ University of Colorado Boulder
}

Please address all correspondence to:

Kathy Escamilla, Ph.D.

University of Colorado, Boulder

BUENO Center

249 UCB, School of Education

Boulder, CO 80309-0249

303-492-0147

FAX 303-492-2883 


\title{
What Gets Lost When English Only Writing Assessment Is Used to Assess Writing Proficiency in Spanish-English Emerging Bilingual Learners?
}

\begin{abstract}
Recent analyses of wide-scale writing assessment outcomes indicate that English writing achievement for fourth and fifth grade emerging bilingual learners continues to be an area of great concern. Utilizing the theory of holistic bilingualism and a mixed methods design, this study examines the writing skills of 44 emerging bilingual fourth and fifth graders. The purpose of this paper was to compare and correlate various writing outcomes as measured by the state's high stakes writing assessment, English language proficiency writing assessment, and an informal biliterate writing rubric. Results indicate that the majority of students are not acquiring proficiency in English writing as measured by English-only assessments. When students' Spanish and English outcomes are considered holistically, students' outcomes in Spanish surpassed English for the majority. Findings indicate the potential for a writing assessment protocol that is intentionally biliterate and that displays Spanish and English, together as a part of the assessment process.
\end{abstract}

Keywords: Elementary Bilingual Education, Biliterate Writing Development, Paired Literacy Word count: 6,684 


\section{Introduction}

Recent analyses of various writing assessments indicate that writing achievement for fourth and fifth grade students is an area of great concern for all students, but most especially for those students labeled as emerging bilingual ${ }^{1}$ learners. To illustrate this concern, in the state where this study took place only $53 \%$ of the fourth graders and $57 \%$ of the fifth graders were deemed to be proficient or advanced in writing in 2014. For emerging bilingual children, the percent drops to $20 \%$ proficient or advanced in fourth grade and $22 \%$ in fifth grade (Colorado Department of Education, 2015). The fact that nearly half of the state's fourth and fifth graders aren't considered to be proficient in writing has created a great deal of anxiety among educators and policy makers in the state and this anxiety is exacerbated by the perceived gap in achievement between emerging bilingual children and others especially in school districts that have large and growing numbers of emerging bilingual children.

Many researchers and writers have eloquently and convincingly argued against the use of high stakes tests as the only measures to assess children's writing abilities no matter whether they are monolingual English speakers or emerging bilingual children (Horn \& Wilburn, 2013; Hursh, 2008; Nichols \& Berliner, 2007). However, as the United States enters into the first phase of the implementation of the Common Core State Standards (CCSS) and the large scale assessments that will be used to measure whether or not students have met these standards, it is unlikely that the practice of assessing student writing proficiency via one high stakes test will diminish in the near future. Further, given that the language arts standards and their

\footnotetext{
${ }^{1}$ Throughout this paper, we use the term emerging bilingual learners as this term reflects the focus of the paper that argues that children who enter school with some knowledge of two languages have a bilingual advantage that should be nurtured and developed in school. The term is a more apt description than the more common and reductive term English learners or English language learners.
} 
accompanying wide scale assessments have been developed only in English, it is also likely that many schools and districts will be pressured to emphasize the teaching and learning of writing in English for emerging bilingual students, even in dual language and bilingual schools. Equally as problematic is the fact that the writing proficiency of emerging bilingual students will also likely continue to be compared to that of monolingual English students creating invalid comparisons and judgments about the quality of schools, teachers, and programs serving emerging bilingual students. In short, the new CCSS with its unapologetic focus on English standards might possibly have the same, albeit unintended effect, of devaluing the language and cultures of children of immigrants in the same way as English immersion programs have done (Berliner \& Glass, 2014).

The purpose of this paper is to add to the literature that raises serious concerns about current writing assessment practices for emerging bilingual children as being not only invalid and unreliable for assessing the writing proficiency or development of these children, but also quite possibly underestimating children's biliterate writing thereby negating their biliterate advantage. The potential for underestimating children's biliterate skills is even greater given that CCSS and English language proficiency assessments are almost exclusively conducted in English and are almost always read and evaluated by monolingual English raters. In this paper we will argue that failure to evaluate children's writing proficiency in two languages for children in bilingual and dual language programs along with the lack of the utilization of a bilingual lens when evaluating the writing of emerging bilingual children in English likely ensures that children will be viewed as less proficient and less capable than they likely are.

This paper examines the writing outcomes of 23 fourth graders and 21 fifth graders who have been instructed bilingually for three to four years in a paired literacy program ${ }^{2}$ and

\footnotetext{
${ }^{2} \mathrm{We}$ are masking the name of the program for initial review of this manuscript.
} 
examines their outcomes on three writing assessment tasks, the state high stakes tests (TCAP), the state language proficiency assessment (ACCESS), and the paired literacy program's Spanish/English biliterate writing assessment.

\section{Theoretical Framework}

The holistic view of bilingualism is the theoretical framework utilized in this study. This theory stresses the importance for teachers to know emerging bilingual children as bilinguals and for test makers and policy makers to understand the conditions under which bilinguals acquire their languages (Grosjean, 1998, de Jong, 2011). This theoretical framework stresses that all bilinguals' performance on tests may vary according to when and where their languages are learned, whether the person administering the tests shares their language background, and whether assessments are conducted in a monolingual or bilingual mode (de Jong, 2011).

Research to support this theory has illuminated issues that arise when emerging bilingual children are not understood as bilinguals. de Jong (2011), for example, synthesizes the research on vocabulary development that compares vocabulary development between monolingual and emerging bilingual children. Generally these studies have concluded that emerging bilingual children have lower vocabulary scores than monolingual students. Work by Oller, Pearson, and Cobo-Lewis (2007) and Bialystok (2009) challenge the results of these vocabulary tests from a bilingual perspective by concluding that presenting the data in one language, such as most of these studies did, tells only half of the story for bilinguals because these studies may not show what the child knows when combining the two languages. They conclude that the distributive nature of bilingual proficiency makes it imperative that a bilingual child's vocabulary be considered across two languages, not just one.

Another consideration is the measurement of conceptual knowledge (what words refer to) 
against that of lexical knowledge (the actual words). Bilinguals may have smaller vocabularies in each language (lexical items) but across language may have comparable vocabulary and a comparable conceptual framework to draw from (Oller \& Eilers, 2002; Pearson, Fernández, \& Oller, 1995).

In this study, we argue that the same can be said for biliterate writing development in emerging bilingual children. Because of the emphasis given on testing outcomes in $21^{\text {st }}$ century schools, especially the emphasis on reading and writing, and because of everything we know about how the bilingual brain develops and how this may vary from monolingualism, it is important that we critically examine the limits of monolingual testing systems and how they are used for emerging bilingual children.

Two studies by Author $(2000,2006)$ provide examples of the limits of monolingual frameworks in understand emerging biliteracy development in reading and writing. In her 2000 study, she uses the example of Leticia, a third grader who scored at the $40^{\text {th }}$ percentile in Spanish on La Prueba, a Spanish language achievement test and at the $25^{\text {th }}$ percentile on the Iowa Test of Basic Skills. The teacher's conclusion was that Leticia read poorly in both languages and that learning in two languages caused her confusion. Alfredo, a monolingual English student in the same class scored at the $40^{\text {th }}$ percentile in English. This time the teachers interpretation was that he was doing fine and he was one of her better readers. The absence of a bilingual perspective devalued Leticia's native language reading skills and her label as a "poor reader" may have lead to low expectations and inappropriate instruction.

de Jong (2011) adds to this framework the importance of understanding school contexts in order to better understand biliterate development. If a school chooses to have a bilingual program, such as the school in this study, and if acquisition of biliteracy is a goal for students, 
then it is important to consider how the acquisition of bilingualism/biliteracy will be taught and assessed. A holistic view of bilingualism calls for a curriculum and assessment system that focuses on the development of communicative competence across two languages. Through the curriculum, instruction, and assessment, schools should identify the purposes for which they want students to be able to use their languages and then provide meaningful opportunities to develop these skills. Assessment should reflect the linguistic repertoires taught in the curriculum.

Assessment frameworks in bilingual/dual language schools similarly must recognize the need to provide opportunities for students to demonstrate what they know through their entire bilingual linguistic repertoire by assessing in both languages. de Jong (2011) sums up this argument nicely by stating that monolingual testing practices will not encourage biliteracy development.

\section{Research Questions}

1. Is there a relationship between the English writing outcomes of fourth and fifth grade emerging bilingual children participating in the paired literacy program based on the TCAP, the ACCESS and the biliterate writing rubric? If so, what can be inferred from these outcomes about the writing proficiency of emerging bilingual fourth and fifth graders?

2. Is there a relationship between the Spanish writing outcomes of fourth and fifth grade emerging bilingual children participating in the paired literacy program and the English writing outcomes on TCAP and ACCESS? If so, what can be inferred from these outcomes about the writing proficiency of emerging bilingual fourth and fifth graders?

3. Does biliterate writing assessment in Spanish and English enhance understandings of writing development of emerging bilingual fourth and fifth graders? If so, in what ways? 


\section{Strategy of Inquiry}

This study compares writing outcomes of 44 , fourth and fifth grade emerging bilingual students who have participated in a paired literacy program since 2011-2012. In this study it was important to understand how these children's English writing would be viewed in light of two high stakes English writing assessment measures and then to view these same children on an informal writing assessment that assesses writing in Spanish as well as English. In this regard data were collected on the children's performance on the Transitional Colorado Assessment Program (TCAP) as well as the Assessing Communication and Comprehension in English (ACCESS) writing assessment. The TCAP is the large-scale assessment that all Colorado students must meet in order to assess whether or not schools and school districts are meeting state content standards. ACCESS is the assessment that children labeled as English language learners (emerging bilingual children) must take in order to determine their levels of proficiency in English. Children in this study also took the paired literacy program's writing Assessment in English and Spanish to examine their writing content and skill development in both Spanish and English. To address Research Questions 1 and 2 correlations were run to establish relationships between outcomes on the TCAP writing, the ACCESS writing outcomes for ELLs, and the biliterate writing rubric. Results from these analyses provided information related to what can be understood and interpreted about student writing progress on three different measures, as well as an understanding of how the three assessments correlate to one another. Further, to address Research Question 2, the results on the TCAP writing, and ACCESS writing were correlated to the Spanish outcomes on the biliterate writing rubric to ascertain what might be added if Spanish writing outcomes were considered as a measure of writing proficiency. To address Research Question 3, we used the outcomes on the biliterate writing rubric in Spanish and English and 
plotted children's growth across three academic years. We also randomly selected children who were labeled as partially proficient on the TCAP writing and Level 4 on ACCESS writing (also partially proficient) and did a qualitative analysis or their writing in English and Spanish to ascertain what biliterate assessment may add to our understanding of children's writing development in two languages.

\section{Paired Literacy Program}

The paired literacy program is an innovative approach to bilingual/dual language education wherein participating students receive paired literacy instruction in both Spanish and literacy-based English language development (ELD) instruction daily beginning in kindergarten. In addition to paired literacy instruction, explicit connections between Spanish literacy and literacy-based ELD (cross-language connections) are part of the instructional routines in order to reinforce literacy knowledge and skills across languages without being duplicative. Within the daily-allotted Spanish literacy and literacy-based ELD instruction, time spent in reading and writing is equal, and explicit and interactive reading and writing instructional approaches are utilized. These approaches include modeled, shared, and collaborative reading and writing opportunities, while also attending to oracy and metalanguage instruction in both language environments. Oracy instruction includes the teaching of oral language skills needed to successfully interact with text and includes vocabulary, language structures, and dialogue. Explicit attention to cross-language connections is provided via metalanguage, where students learn to analyze each language (its sounds, symbols, grammar, vocabulary, and structures) separately, as well as to understand the relationship between languages in the context of reading and writing activities. 
The paired literacy program began as an exploratory study in 2004 and was pilot tested in 2005. It continued into its first formal phase as a longitudinal study from 2006 to 2009, which included a total of 19 schools in seven school districts in two states. Phase II began in 2009, and it consisted of two parts: a case study including three schools in Colorado, which was meant to allow for a deeper investigation of fidelity of implementation, and a replication study in the Pacific Northwest, which was meant to replicate the first phase and to provide additional empirical evidence regarding the efficacy of the program. The paired literacy program is now in its third phase of development and implementation and has to date served over 5,000 children and 250 teachers.

\section{The Study Site}

The current study utilizes data from one of the case study schools. This particular school began its implementation of paired literacy in 2011-2012 and prior to the program implemented an early exit transitional native language bilingual program which instructed students in Spanish for the first few grades with the expectation that students would be transitioned into English-only instruction as quickly as possible.

The elementary enrolls students in early childhood education (ECE) through fifth grade and had a total enrollment of 511 K-5 students in 2013-14. The school population was approximately 88\% Latino, four percent White, two percent Asian, one percent AfricanAmerican, and one percent Native American. Emerging bilingual children made up $65 \%$ of the student population. Ninety eight percent of the school's students participated in the free or reduced priced $(\mathrm{FRL})$ program.

\section{Data Sources}

The following data sources were used in the study. 
Transitional Colorado Assessment Program (TCAP). The TCAP has been Colorado's standard's based assessment since 2011. The TCAP replaced the Colorado Student Assessment Program (CSAP). Both assessments were designed to provide a picture of student performance to schools, districts, educators, parents, and the community (www.cde.state.co.us/assessment/coass - accessed 2/10/15). The TCAP assesses the Model Content Standards that are aligned with the Colorado Academic Standards. The TCAP also assesses some Model Content Standards that are not in the Colorado Academic Standards, but were deemed necessary in order to preserve the year-to-year comparability of the TCAP to the CSAP.

TCAP is available in reading and writing in Spanish as well as English in the third and fourth grade, but all students are expected to take the assessment in English in the fifth grade. As an illustration of the pressure to assess students in English, 1,400 emerging bilingual children took the third grade writing assessment of TCAP in 2014, but only 155 took the Spanish writing assessment in fourth grade. There were no children at the study school who took the TCAP in Spanish in fourth grade. The TCAP is administered annually in English in March. Beginning in school year 2014-2015 the TCAP will be replaced by the Partnership for Assessment of Readiness for College and Careers (PARCC).

Assessing Comprehension and Communication in English (ACCESS) Assessment. ACCESS for ELLs (Assessing Comprehension and Communication in English State-to-State for English Language Learners) is a secure large-scale English language proficiency assessment given to children in kindergarten through grade 12 who have been identified as English language learners (ELLs). It was developed by researchers at the World Class Instructional Design and Assessment (WIDA) group and is given annually in WIDA Consortium member states to monitor students' progress in acquiring academic English. ACCESS is administered in January to 
all eligible students state-wide. The writing assessment is conducted via the gathering of a writing sample based on a writing prompt and scored on a writing rubric that has six levels of proficiency (entering, beginning, developing, expanding, bridging, and reaching) and it assesses three types of written proficiency including linguistic complexity, vocabulary usage, and language control (http://www.wida.us-). Students who score at the bridging level (level 5) are considered to be proficient English writers.

Biliterate Writing Rubric. The biliterate writing rubric in Spanish and English (see Appendix A) was created to assess the Spanish and English writing of emerging bilingual students in the elementary grades, and it allows for the recording of Spanish and English writing scores on a single rubric. The quantitative portion of the rubric consists of three linguistic constructs with a total of 21 points: content (0-10), structural elements (0-5), and spelling (0-6). This rubric was purposefully designed to distribute weight differently to each construct. The ability to communicate a message, as measured in the content construct, carries more weight than spelling words correctly or using standard conventions. The biliterate writing rubric was developed to simultaneously display Spanish, English and bilingual language knowledge and strategies that students demonstrate in their writing.

Content and construct validity was established for the biliterate writing rubric. Construct validity was established by examining and comparing the rubric to similar writing rubrics created for students learning to write in Spanish and English in U.S. contexts (e.g. 6+1 Trait Writing ${ }^{\circledR}$ rubric in Spanish and English, Culham, 2003; and the Authentic Literacy Assessment System (ALAS) in English and Spanish, García, 2005). Constructs on similar rubrics establish that the assessment of writing should include content, conventions, and spelling in each of the languages being assessed. 


\section{Findings}

Research Question 1 asked, "Is there a relationship between the English writing outcomes of fourth and fifth grade emerging bilingual children participating in the paired literacy program based on the TCAP, the ACCESS and the biliterate writing rubric?" If so, what can be inferred from these outcomes about the writing proficiency of emerging bilingual fourth and fifth graders?

To address this question, we first examined the outcomes on the TCAP and the ACCESS to determine how the outcomes would likely be judged if the students were to only be evaluated on their English outcomes. We did not include outcomes on the biliterate writing rubric as we only assess student writing outcomes when we compare English and Spanish together. These outcomes will be discussed as a part of Research Questions 2 and 3. We then ran correlations to determine the extent to which what is measured on one assessment is related to what is measured on the next. In this analysis we included the biliterate writing rubric in English to determine its correlation to more commonly used high stakes measures. Table 1 represents student outcomes on the TCAP, Table 2 on the ACCESS and Table 3 on the correlations between TCAP, ACCESS and the biliterate writing rubric in English.

\section{[INSERT TABLE 1 NEAR HERE]}

When reading these findings it is important to note that only students who are considered to be proficient or advanced are counted as having met the writing standards in any grade level. With regard to Table 1 results indicated that in the fourth grade only $13 \%$ of the students were deemed proficient and only $19 \%$ of the students in the fifth grade were deemed proficient. However, it is also noteworthy that $65 \%$ of the children in the fourth grade and $67 \%$ in the fifth grade are considered to be partially proficient and perhaps nearing proficiency. This is 
noteworthy given that these students are learning to write in a language that is a second language to them, a point we will return to in the discussion. Further, the TCAP was created for and normed on monolingual English children and its criteria for proficiency is based on monolingual English children and not emerging bilingual children who are learning English as an additional language. Nonetheless, reading these outcomes as they are presented without nuanced interpretation might lead one to believe that there is cause for concern about the writing achievement of these emerging bilingual children and perhaps their biliteracy development should be set aside to be replaced by a focus on English.

\section{[INSERT TABLE 2 NEAR HERE]}

As noted above, the ACCESS is an assessment that was created specifically for emerging bilingual children and in this assessment, children are considered to be proficient in English writing when they achieve a Level 5 (Bridging). Using this assessment to examine student outcomes, we note that more children are considered to be proficient at each grade level (52\% in fourth grade and 33\% in fifth grade). As with the TCAP outcomes, one also notes that there are also significant percentages of students at Level 4 (on the cusp of proficiency). This includes $39 \%$ of the fourth grade students and $48 \%$ of the fifth grade students. Since this writing assessment was created to examine the writing growth and proficiency of students who are labeled as English language learners, it is not surprising that more students are considered to be proficient English writers using this measure, however again, reading these outcomes without nuanced interpretation would also lead us to believe that a majority of emerging bilingual children in this school were not doing well in English writing and becoming proficient in English.

\section{[INSERT TABLE 3 NEAR HERE]}

In order to better interpret the writing outcomes of children in this study, it was also 
important to understand the degree to which the three assessments used in English were related. Table 3 illustrates the correlations between the TCAP, the ACCESS, and the biliterate writing rubric for children in this study at the fourth and fifth grade levels. For all three correlations at both grade levels these correlation coefficients are high and positive indicating that comparisons across assessments is appropriate. Further, these findings indicate that a biliterate assessment such as the biliterate writing rubric may be important in demonstrating what informal biliterate assessments can add to our understand of children's writing development in two languages rather than just in English.

Research Question 2 asked, "Is there a relationship between the Spanish writing outcomes of fourth and fifth grade emerging bilingual children participating in the paired literacy program and the English writing outcomes on TCAP and ACCESS? If so, what can be inferred from these outcomes about the writing proficiency of emerging bilingual fourth and fifth graders?" To address this question, we examined the correlations between the Spanish writing outcomes on the biliterate writing rubric and the English outcomes on the TCAP and ACCESS. We start by presenting the mean scores on the biliterate writing rubric (see Table 4). We then ran correlations to determine the extent to which student writing performance in Spanish on the biliterate writing rubric may be related to the English outcomes on TCAP and ACCESS (Table 5).

Findings presented in Table 4 indicate that, in this particular program, children's writing outcomes in English and Spanish are very close indicating that while the majority of children may be considered to be behind when one uses a monolingual English lens, using a biliterate lens, they are more properly labeled an emerging biliterate learner. An important finding in this study is that when one only looks at emerging bilingual children's writing in English one of the things 
that gets lost is the value for emerging biliteracy.

\section{[INSERT TABLE 4 NEAR HERE]}

Findings presented in Table 5 are added to look at the relationships that may exist between Spanish writing assessments (such as the biliterate writing rubric) and its companion English writing rubric and English high stakes writing assessments such as the TCAP and ACCESS. Results indicate that there is a high and positive correlation between both fourth and fifth grade Spanish writing and results on the TCAP, ACCESS and biliterate English writing rubric. While the correlations between the biliterate Spanish rubric and ACCESS and TCAP are lower than these same correlations in English, they are still quite high. To be specific, in fourth grade the TCAP/biliterate writing rubric correlation coefficients are .73 for English and .67 for Spanish indicating that the writing achievement in Spanish is highly related to English. For fifth grade the coefficients are .85 in English and .77 in Spanish suggesting the same trend.

\section{[INSERT TABLE 5 NEAR HERE]}

A similar finding is reported for the correlation between the English ACCESS assessment and the biliterate writing rubric outcomes. For fourth grade the relationship between the English scores as measured by the biliterate writing rubric and ACCESS is .80 and between the Spanish scores on the biliterate writing rubric and ACCESS it is .72. In fifth grade these outcomes are .62 and .65 respectively. It is noteworthy that at fifth grade there is a higher correlation between the Spanish biliterate writing rubric outcomes and the ACCESS outcomes than in English suggesting that there is a correlation between Spanish and English writing and the better writers in Spanish also become the stronger writers in English at both grade levels.

Research Question 3 asked, "Does biliterate writing assessment in Spanish and English enhance understandings of writing development of emerging bilingual fourth and fifth graders? 
If so, in what ways?" To address Research Question 3, we examined the writing progress of children in the study across three academic years using the biliterate writing rubric in Spanish and English. For fourth grade students this meant examining second, third, and fourth grade outcomes and for fifth grade students, third, fourth, and fifth grades outcomes were examined (mean outcomes are reported in Table 6 and illustrated in Figures 1 and 2). While Figures 1 and 2 illustrate different trends for each cohort group of students, each illustrates that children's writing development is closely connected between languages and across time. Figure 1 illustrates that students in the study made steady and continuous growth as measured by the biliterate writing rubric in Spanish and English across years and are becoming biliterate writers. Moreover, the graph indicates the cumulative benefits of being in a long-term bilingual/biliterate program. The nascent and growing biliteracy in these children would have been lost if the schools had quit teaching literacy in Spanish in order to focus on English.

\section{[INSERT TABLE 6 AND FIGURES 1 AND 2 NEAR HERE]}

A final qualitative analysis was done on children who are not yet considered to be proficient in English writing (and yet are on the cusp of proficiency) and whose writing might be grossly under rated if accompanying writing samples were not collected and analyzed in Spanish. Further, this qualitative analysis enabled us to examine what might be lost if English writing is read and rated by monolingual English raters (as is frequently the case). We selected writing samples for additional qualitative analysis if children scored at the partially proficient level on TCAP and at Level 4 or below on ACCESS. For this study, this amounted to nine students at the fifth grade level and four at the fourth grade ( $\mathrm{n}=13$ ). To illustrate this finding, we present the biliterate writing samples of Victoria.

Victoria was a fourth grade student at the time these writing samples were collected. In 
her TCAP writing she was considered to be Partially Proficient and her ACCESS writing was a Level 4 (Expanding) indicating partial proficiency in writing. Her composite overall composite score as measured by the biliterate writing rubric is 15 in both English and Spanish, indicating that she is biliterate, which in and of itself is a more positive label than either partially proficient or expanding. Her writing samples in both English and Spanish are presented in Figure 3. The English is presented first to illustrate what happens when children's writing is examined and judged only in one language.

\section{[INSERT FIGURE 3 NEAR HERE]}

In Victoria's English writing sample, she has a clear introduction and conclusion. She utilizes the structure of sequence with transition words to explain why she wants to be her brother. Her sentences are complex but follow the same structure of: One reason... Another reason $I$... The next to last sentence is complex and she uses appropriate punctuation: "The last reason that I will like to be my brother is that he can gow by him self to the park to walk the dogs, and I cannot walk the dogs by my self." While Victoria has a strong and complex introductory sentence, "all cans of persons I could be", the use of "cans" instead of "kinds" might be marked down by monolingual raters for not understanding the spelling of the word and not inferring the meaning. Further, the incorrect grammar used in the next sentence, "I will like to be..." with the use of "will" for would might also be marked down by monolingual raters even though this approximation is quite common for emerging bilingual learners. Her writing also illustrates spelling approximations that are both Spanish influenced as well as approximations that are common in the writing of monolingual English children. Spanish influenced approximations include: cains/kinds; pulls/pools; wy/why. Common English approximations include: althogh/although; any wear/anywhere; wont's/wants; cradict/credit; and gow/go. Both because 
of the frequency of spelling errors and the combination of English and Spanish influenced approximations, a monolingual rater may well see this child as a less proficient writer than she is.

We get a different and more complete picture of Victoria when we add her Spanish writing sample. For example, we note that she uses much more descriptive language in Spanish. She uses the word tiernos (tender), and says, "Tiene un perro color blanco con puntitos negros $y$ es chiquito." (She has a white dog with black spots and he is small). In her Spanish writing we note that she wrote two paragraphs, although she knows how to use indentation in both samples. She also uses the question mark correctly. In Spanish she does some interesting hyposegmentation of words (nomas/no más; aveses/a veces) which is the opposite of what she does in English with compound words (any wear/anywhere). Her Spanish writing is not without spelling errors (dise/dice; por que/porque; pasiar/pasear; si/sî), however these are very common misspelled words for Spanish writers and would not get in the way of a rater understanding what she was trying to communicate. Overall, through analysis of both of her writing samples, we get a more complete picture of her abilities and development and she her as more capable than if we only analyzed English.

Our findings for Victoria are similar for the other 12 students who were at the same levels in English ACCESS and TCAP. In fact, when we add qualitative writing analysis of Spanish to what students produce in English we found evidence that the Spanish samples tended to have the following features that were absent in English: 1) The Spanish samples had an introduction and a conclusion; 2) The Spanish samples exhibited greater grammatical complexity; 3) The Spanish samples have more varied transitional phrases and varied language structures; and 4) The Spanish samples have greater use of conventional syntax. $n$ short, much is lost if Spanish isn't considered along side English. 


\section{Discussion}

Findings from this study indicate that when emerging bilingual children are given opportunities to learn to write in both English and Spanish, their outcomes in Spanish are more likely to surpass their English outcomes and their English outcomes likely make them appear that they are less proficient writers than they, in fact are. English writing outcomes, then, are more a product of lack of proficiency in English than poor writing ability. This is significant for several reasons. If the students' writing ability is underestimated, that is, the totality of their biliterate writing abilities are not considered, then instruction is likely to be inappropriate and may be at a lower instructional level, when it should be at a higher level in order to build upon what is known in both languages. Using the example of Victoria, if her instructional program is based solely on her writing outcomes in English, a teacher could conclude that she does not have a good handle on spelling and grammatical conventions. A teacher might also conclude that Victoria only has social English and needs to develop more academic English. Adding her Spanish writing sample to her English writing samples demonstrates that she, in fact, controls complex grammatical language, she has a good knowledge of conventions that she needs to be encouraged to apply in English, and that many of her English spelling approximations will likely dissipate with more practice writing in English. Further, her use of social English in both Spanish and English were likely a result of the prompt and should not be attributed to a perceived deficiency in her writing.

While the number of students in this study is low, the high correlation between Spanish and English writing demonstrates the value of continuing to teach children to read and write in Spanish as well as English even beyond the third grade. In fact, findings from this study raise concerns about the widespread practice of second and third grade transition to English-only in 
bilingual programs, and/or of English emphasis in many dual language programs at the fourth and fifth grade levels. Further, given the high and positive correlations between the biliterate writing rubric and the English TCAP and ACCESS assessments, findings indicate the potential for a writing assessment protocol that is intentionally biliterate and that displays Spanish, English, and biliteracy together as a part of the assessment process. Studies across several decades have documented the interconnectedness of two languages for bilingual learners. These studies have found that literacy skills learned in one language are strongly correlated to literacy levels developed in an additional language both for languages that have the same alphabet as well as between languages with different orthographies (Cummins, 2000; Oller \& Eilers, 2002; Montanari, Simón-Cereijido, \& Hartell, 2016). Additional studies have documented that language interconnectedness is also bidirectional (Cook, 2003; Gort, 2008). In short, one might conclude that failure to consider the development of students' literacy development in two languages means that we cannot understand fully how children are using their two languages to learn, thereby restricting our ability to provide instruction that accelerates this learning.

Findings from this study provide additional support for the value of using a formative assessment tool such as the biliterate writing rubric in addition to the more summative assessments such as TCAP and ACCESS. In fact, a tool such as the biliterate writing rubric can serve both a summative and formative purpose for assessing the writing development of emerging bilingual children, and as stated above, schools that purport to be bilingual must have valid and reliable means for their children to demonstrate their emerging biliteracy. In the biliterate writing rubric, children's ideas and voice are weighted more heavily than conventions and spelling. Findings from this study indicate that this weighting may also help to uncover and value the writing of emerging bilingual children in a way that does not underestimate their 
achievements. We agree with Váldes \& Figueroa (1996) in their assertion that perhaps the most insidious psychological damage to second language learners is the current high stakes English only testing environment in the U.S.

Aside from the need to better understand how to interpret writing development and progress of emerging bilingual children, there is a need for schools to continue to study ways to encourage children to become biliterate and to embark on long-term efforts to promote biliteracy. The school where this study took place is committed to biliteracy development, but the pressure to produce results in English is, at times, almost unbearable for teachers and leaders at the school. Ironically, the pressure to produce in English flies in the face of the abundance of current research that establishes the benefits of bilingualism. A few examples of these research findings illustrate this point and include: 1) Bilingually educated students have greater cognitive flexibility, working memory, and executive functioning (Bialystok, 2001); 2) Bilingually raised students have more cohesive family relations and fewer behavior problems in school (Portes \& Hao, 2002); 3) Students who maintain their bilingualism into high school are more likely to go to 4-year colleges (Santibañez \& Zárate, 2014); 4) Students who maintain bilingualism into high school are less likely to drop-out (Rumbaut, 2014); and 5) Young students who maintain bilingualism will earn more in the labor force than their monolingual peers (Agirdag, 2014).

As the U.S. enters into the Common Core State Standards and assessments era, it is important to understand how our current English only language arts standards and their accompanying high stakes English only assessments may short change emerging bilingual children and may not in fact prepare them for college and careers that will be needed for the $21^{\text {st }}$ century. Much can be lost and misunderstood when English only assessment practices are applied to the writing development of emerging bilingual students, however, the converse is also 
true. Biliteracy writing assessment for those children, who are fortunate enough to attend schools that are actively developing their bilingual advantage, illustrates that much can be gained. 


\section{References}

Agirdag, O. (2014). The literal cost of language assimilation for the children of immigration:

The effects of bilingualism on labor market outcomes, in Callahan, R. \& Gándara, P. (Eds.), The bilingual advantage: Language, literacy and the U.S. labor market (pp. 162-

182). Bristol, UK: Multilingual Matters

Author. (2000).

Author. (2006).

Authors. (2014).

Berliner, D., \& Glass, G. (2014). 50 myths \& lies that threaten America's public schools. New York: Teacher's College Press.

Bialystock, E. (2001). Bilingualism in development: Language, literacy, and cognition. New York: Cambridge University Press.

Bialystok, E. (2009). Bilingualism: The good, the bad and the indifferent. Language and Cognition, 12(1), 3-11.

Colorado Department of Education (2015). www.cde.state.co.us/assessment/coass - accessed $2 / 10 / 15)$

Cook, V. (Ed.). (2003). Effects of the second language on the first. Clevedon, UK: Multilingual Matters.

Cummins, J. (2000). Language, power and pedagogy: Bilingual children in the crossfire (Vol 23). Clevedon, UK: Multilingual Matters.

Culham, R. (2003). 6+1 traits of writing: The complete guide grades 3 and up. New York: Scholastic.

de Jong, E. (2011). Foundation for multilingualism in education. Philadelphia: Caslon. 
García, E. E. (2005). Teaching and learning in two languages. New York: Teachers College Press.

Gort, M. (2008). "You gave me idea!" Collaborative strides toward bilingualism, biliteracy, and cross-cultural understanding in a two-way partial immersion program. Multicultural Perspectives, 10(4), 192-2000.

Grosjean, F. (1998). Studying bilinguals: Methodological and conceptual issues. Bilingualism, Language and Cognition. 50, 131-149.

Horn, J., \& Wilburn, D. (2013). The mismeasurement of education. Charlotte, NC: Information Age Publishing.

Hursh, D. (2008). High-stakes testing and the decline of teaching and learning: The real crisis in Education. Lanham, MD: Rowman \& Littlefield.

Montanari, S., Simón-Cereijido, G., \& Hartel, A. (2016). The development of writing skills in an Italian-English two-way immersion program: Evidence from first through fifth grade. International Multilingual Research Journal, 10,(1), 44-58.

Nichols, S., \& Berliner, D. (2007). Collateral damage: How high-stakes testing corrupts American education. Cambridge, MA: Harvard Education Press.

Oller, D., \& Eilers, R. (Eds.) (2002). Language and literacy in bilingual children. Clevedon: Multilingual Matters.

Oller, D., Pearson, B., Cobo-Lewis, A. (2007). Profile effects in early bilingual language and literacy. Applied Psycholinguistics, 28, 191-280.

Pearson, B., Fernández, S. \& Oller, D. (1995). Cross-language synonyms in the lexicon of bilingual infants: One language or two? Journal of Child Language, 22, 345-368. 
Portes , A., \& L. Hao, L. (2002). The price of uniformity: Language, family and personality adjustment in the Immigrant Second Generation. Ethnic and Racial Studies 25(6), 889912.

Rumbaut, R. (2014). English plus: Exploring the socio-economic benefits of bilingualism in Southern California. In Callahan, R. \& Gándara, P. (Eds.), The bilingual advantage: Language, literacy and the U.S. labor market (pp. 184-210). Bristol, UK: Multilingual Matters.

Santibañez, L. \& Zárate, M.E. (2014). Bilinguals in the United States and college enrollment. In Callahan, R. \& Gándara, P. (Eds.), The bilingual advantage: Language, literacy and the U.S. labor market (pp. 213-234). Bristol, UK: Multilingual Matters.

Váldes, G. \& Figueroa, R. (1996). Bilingualism and testing: A special case of bias. Norwood, Ablex.

World Class Instructional Design \& Assessment (WIDA). (http://www.wida.us- accessed Mar. 5, 2015. 


\section{APPENDIX A}

\begin{tabular}{|c|c|c|}
\hline $\begin{array}{l}\text { Rater ID: } \\
\text { Student ID: }\end{array}$ & Biliterate!Writing!Rubric:!Grades!K,!1,!2,!3,!4!\&!5! & \multirow[t]{2}{*}{$\begin{array}{l}\text { Not to promp } \\
\text { (Circle)\$\$\$ } \\
\text { Span } \mid \text { En }\end{array}$} \\
\hline ! & !!!!!!!!!(Circle\$̧Grade)\$ & \\
\hline $\begin{array}{l}\text { SPANISH! } \\
\text { SCORE }\end{array}$ & CONTENT & $\begin{array}{l}\text { ENGLISH! } \\
\text { SCORE! }\end{array}$ \\
\hline $10 !$ & $\begin{array}{l}\text { Focused composition, conveys emotion or uses figurative language, is } \\
\text { engaging to the reader; clearly addresses the prompt; book language }\end{array}$ & $10 !$ \\
\hline $9 !$ & Organization of composition includes effective transitions \& vivid examples & $9 !$ \\
\hline $8 !$ & $\begin{array}{l}\text { Writing includes complex sentence structures and has a discernable, } \\
\text { consistent structure }\end{array}$ & $8 !$ \\
\hline $7 !$ & Sense of completeness - Clear introduction and clear conclusion & $7 !$ \\
\hline $6 !$ & $\begin{array}{l}\text { Includes descriptive language (use of adjectives, adverbs at the word level) } \\
\text { or varied sentence structures }\end{array}$ & $6 !$ \\
\hline $5 !$ & $\begin{array}{l}\text { Main idea discernable with supporting details, or main idea can be inferred } \\
\text { or stated explicitly, or repetitive vocabulary: may include unrelated ideas }\end{array}$ & $5 !$ \\
\hline $4 !$ & 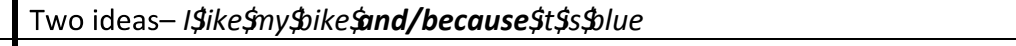 & $4 !$ \\
\hline $3 !$ & $\begin{array}{l}\text { One idea expressed through a subject \& predicate, subject may be implied } \\
\text { (I\$ike\$ny \$oike,\$mo,\$or\$un)\$ }\end{array}$ & $3 !$ \\
\hline $2 !$ & Label(s), list of words. May communicate an idea w/o subject \& predicate & $2 !$ \\
\hline $1 !$ & $\begin{array}{l}\text { Prewriting: Picture only, not readable, or written in a language other than } \\
\text { the prompt }\end{array}$ & $1 !$ \\
\hline $0 !$ & The student did not prepare a sample & $0 !$ \\
\hline & STRUCTURAL!ELEMENTS! & \\
\hline $5 !$ & Multi-paragraph composition with accurate punctuation and capitalization & $5 !$ \\
\hline $4 !$ & Controls most structural elements and includes paragraphing & $4 !$ \\
\hline $3 !$ & $\begin{array}{l}\text { Controls beginning and ending punctuation in ways that make sense and is } \\
\text { attempting additional structural elements (commas, question marks, } \\
\text { guiones, apostrophes, ellipses, parentheses, hyphens, and indentation) }\end{array}$ & $3 !$ \\
\hline $2 !$ & Uses one or more of the structural elements correctly & $2 !$ \\
\hline $1 !$ & Uses one or more of the structural elements incorrectly & $1 !$ \\
\hline 0 ! & Structural elements not evident & $0 !$ \\
\hline & SPELLING! & \\
\hline $6 !$ & Accurate spelling & $6 !$ \\
\hline $5 !$ & Most words are spelled conventionally & $5 !$ \\
\hline $4 !$ & $\begin{array}{l}\text { Majority of HFW are correct and child is approximating standardization in } \\
\text { errors }\end{array}$ & $4 !$ \\
\hline $3 !$ & $\begin{array}{l}\text { Most words are not spelled conventionally but demonstrates an emerging } \\
\text { knowledge of common spelling patterns }\end{array}$ & $3 !$ \\
\hline $2 !$ & $\begin{array}{l}\text { Represents most sounds in words and most high frequency words are } \\
\text { spelled incorrectly }\end{array}$ & $2 !$ \\
\hline $1 !$ & Represents some sounds in words & $1 !$ \\
\hline $0 !$ & Message is not discernable & $0 !$ \\
\hline
\end{tabular}


Figure 1: Longitudinal Biliterate Writing Development, Grades 2-4; 2012-2014

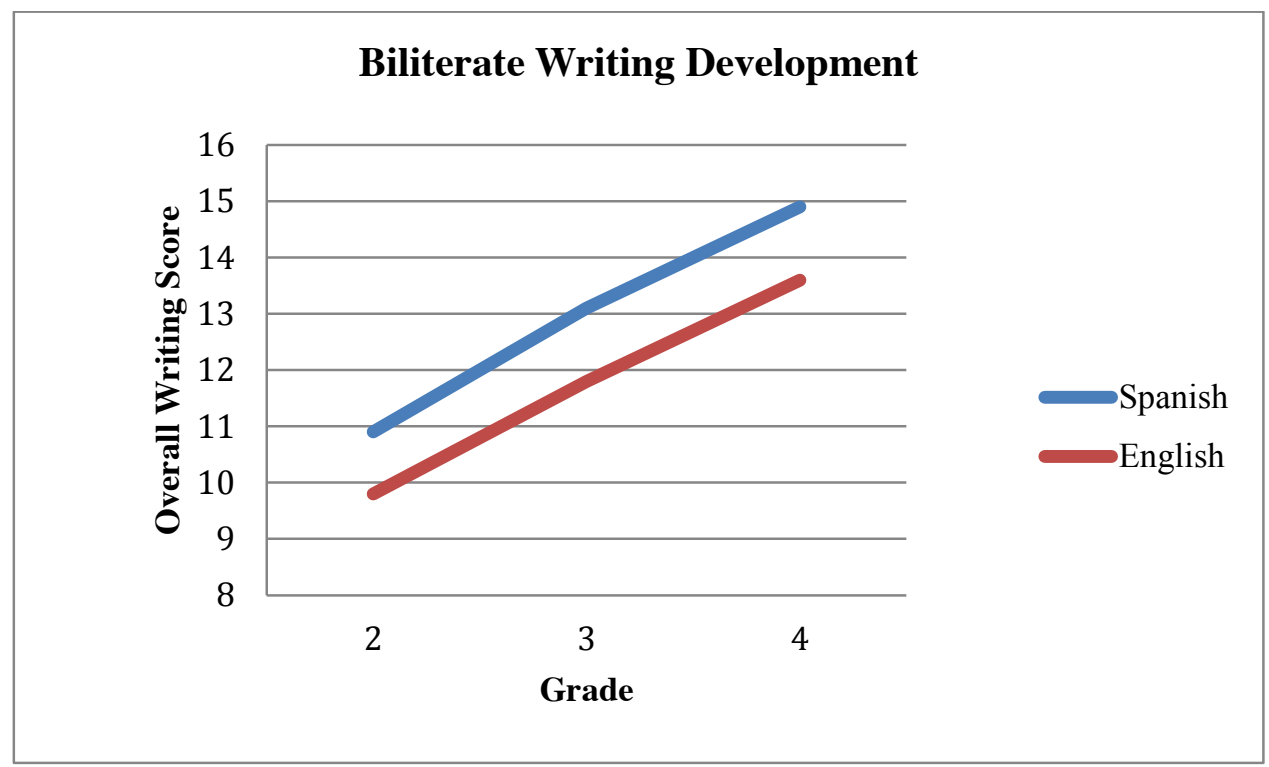


Figure 2: Longitudinal Biliterate Writing Development, Grades 3-5; 2012-2014

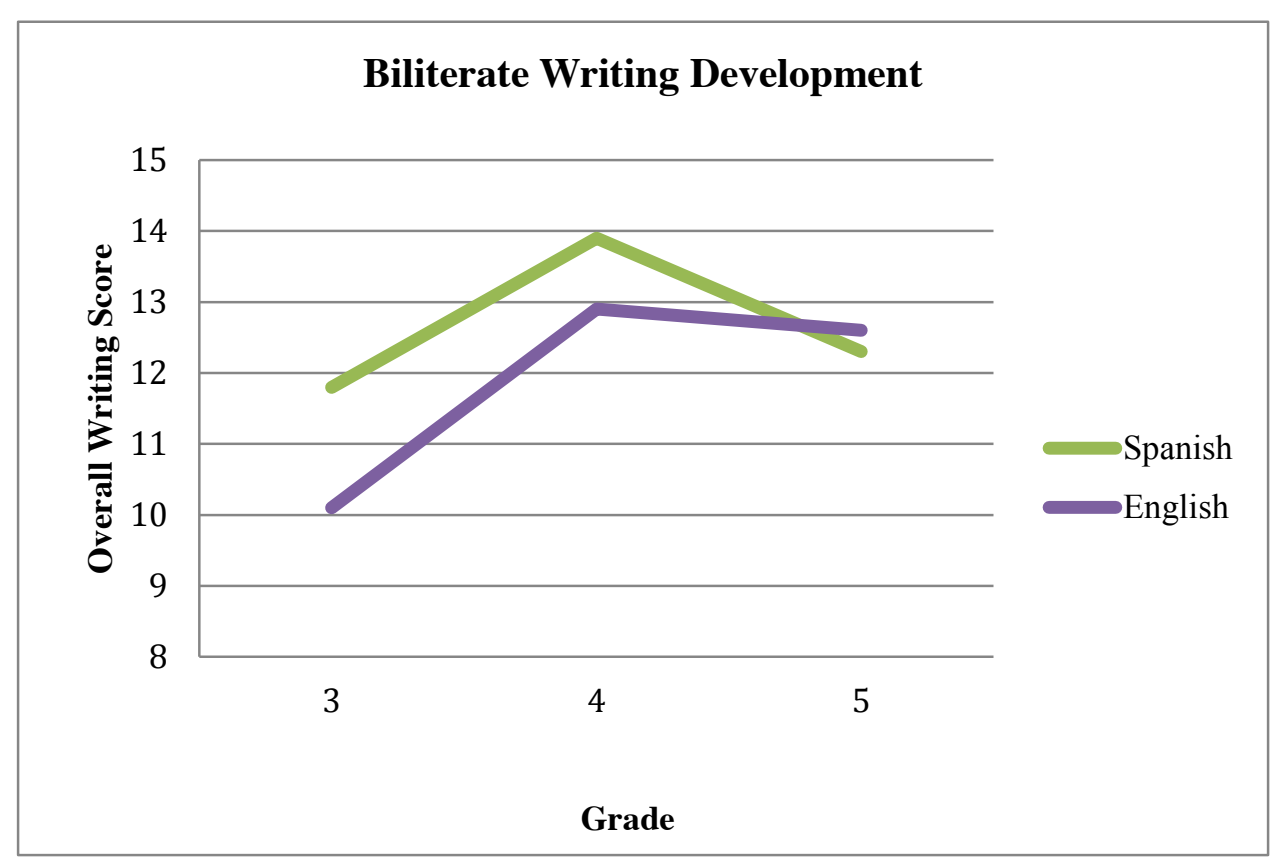


Figure 3. Victoria's Fourth Grade Biliterate Writing Samples

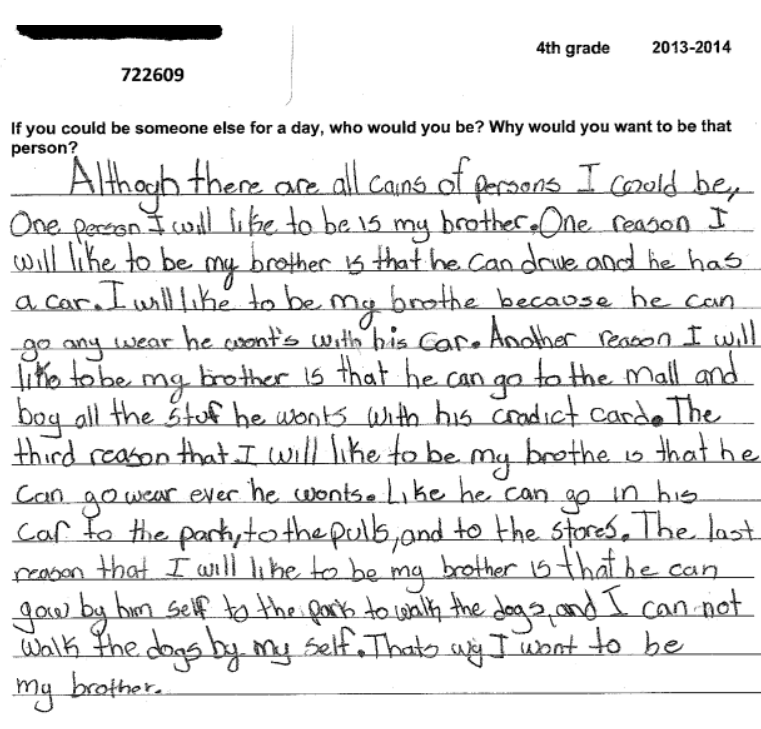

English Translation: Prompt: Who do you consider to be your best friend in the whole world? Write about why that person is your best friend.

In my house across from my house lives my best friend in the whole world and her name is Stephanie. She is very kind to animals because she loves them so much but she doesn't like cats because she is allergic to them. With the animals she is very nice because she says that they are very nice and affectionate. She likes animals because when she grows up she wants to be a veterinarian like me.

She really likes dogs and she also has a dog that is white with black spots and it is little and very pretty. Every time I get to her front door to play at times dogs will pass by and we grab them but we don't keep them as pets we just pet them. When she comes to my how she says Thaily do you want to walk the dogs? And I say yes and our dogs always play together. 
Table 1

Fourth and Fifth Grade Outcomes on TCAP Writing, Spring 2014

\begin{tabular}{lllcc}
\hline Grade & $\mathrm{n}$ & Level & Frequency & Percent \\
\hline 4 & 23 & Unsatisfactory & 5 & $22 \%$ \\
& Partially Proficient & 15 & $65 \%$ \\
& Proficient & 3 & $13 \%$ \\
& Advanced & 0 & 0 \\
\hline 5 & Unsatisfactory & 3 & $14 \%$ \\
& 21 & Partially Proficient & 14 & $67 \%$ \\
& & Proficient & 4 & $19 \%$ \\
& Advanced & 0 & $0 \%$ \\
\hline
\end{tabular}


Table 2

Fourth and Fifth Grade Outcomes on ACCESS Writing, Spring 2014

\begin{tabular}{lllcc}
\hline Grade & $\mathrm{n}$ & ACCESS Level & Frequency & Percent \\
\hline 4 & 23 & Beginning (2) & 1 & $4 \%$ \\
& & Developing (3) & 1 & $4 \%$ \\
& Expanding (4) & 9 & $39 \%$ \\
& & Bridging (5) & 12 & $52 \%$ \\
\hline 5 & Beginning (2) & 1 & $5 \%$ \\
& Developing (3) & 3 & $14 \%$ \\
& 21 & Expanding (4) & 10 & $48 \%$ \\
& & Bridging (5) & 7 & $33 \%$ \\
\hline
\end{tabular}


Table 3

Correlations between TCAP, ACCESS, and Biliterate Writing Rubric, Spring 2014

\begin{tabular}{lllll}
\hline Grade & Assessments & TCAP & ACCESS & $\begin{array}{l}\text { Biliterate English } \\
\text { Rubric } \\
4(n=23)\end{array}$ \\
& TCAP & - & .87 & .73 \\
& ACCESS & .87 & - & .80 \\
& Biliterate English & .73 & .80 & - \\
& Rubric & & & .85 \\
\hline $5(n=21)$ & TCAP & - & -72 & .61 \\
& ACCESS & .72 & .61 & - \\
& Biliterate English & .85 & & \\
\hline
\end{tabular}

*Note: All coefficients are significant $(\mathrm{p}>.01)$ 


\section{Table 4}

Fourth and fifth Grade Mean Scores on Biliterate Writing Rubric in Spanish and English, Spring 2014

\begin{tabular}{llcc}
\hline Grade & Language* & Mean & SD \\
\hline $4(\mathrm{n}=23)$ & Spanish & 14.8 & 2.9 \\
& English & 13.7 & 3.1 \\
\hline \multirow{2}{*}{$5(\mathrm{n}=21)$} & Spanish & 12.6 & 2 \\
& English & 13 & 2.2 \\
\hline
\end{tabular}

*Maximum total points on the composite biliterate writing rubric $=21$ in each language. 


\section{Table 5}

Fourth and Fifth Grade Correlations between TCAP, ACCESS, and the Biliterate Spanish Writing Rubric, Spring 2014

\begin{tabular}{llccc}
\hline Grade & Assessment & TCAP & ACCESS & $\begin{array}{c}\text { Biliterate } \\
\text { English Rubric }\end{array}$ \\
\hline $4(\mathrm{n}=23)$ & $\begin{array}{l}\text { Biliterate } \\
\text { Spanish Rubric }\end{array}$ & .67 & .72 & .73 \\
\hline $5(\mathrm{n}=21)$ & $\begin{array}{l}\text { Biliterate } \\
\text { Spanish Rubric }\end{array}$ & .77 & .65 & .81 \\
\hline
\end{tabular}

*Note: All coefficients are significant $(p>.01)$ 
Table 6

Cohort Biliterate Rubric Writing Growth from 2011-12 through 2013-14

\begin{tabular}{llllll}
\hline $\begin{array}{l}\text { Cohort } \\
\text { (Grades) }\end{array}$ & $n$ & Language & 2012 & 2013 & 2014 \\
\hline Cohort I & 18 & Spanish & 10.9 & 13.1 & 14.9 \\
$(2 / 3 / 4)$ & & English & 9.8 & 11.8 & 13.6 \\
\hline Cohort II & 16 & Spanish & 11.8 & 13.9 & 12.3 \\
$(3 / 4 / 5)$ & & English & 10.1 & 12.9 & 12.6 \\
\hline
\end{tabular}

